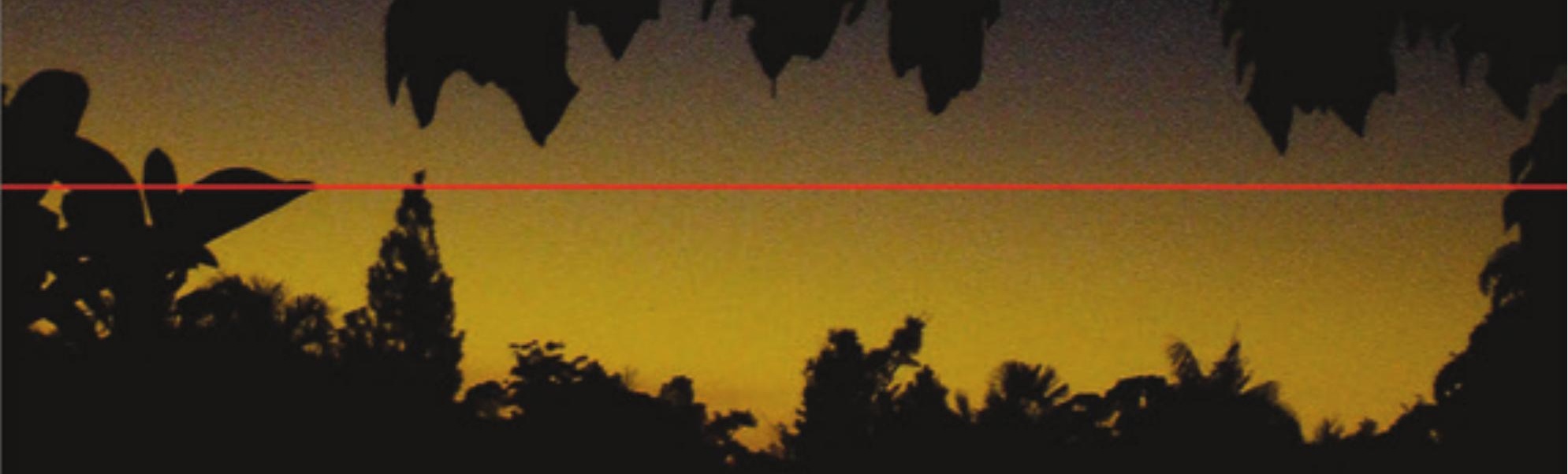




\title{
Passado presente: estudo exploratório sobre a utilização turística do patrimônio arqueológico no Estado do Rio de Janeiro
}

Past present: an exploratory study on the tourist use of archaeological heritage in the State of Rio de Janeiro

\author{
Maria Amália Silva Alves de Oliveira ${ }^{1}$
}




\section{Resumo}

São João Marcos é um sítio arqueológico formado pelas ruínas da cidade de mesmo nome e cuja destruição, para dar lugar a construção de uma usina hidrelétrica, promoveu processo de desocupação para posterior inundação das terras; episódio que fomentou uma memória coletiva da destruição. No presente trabaIho analisa-se a experiência de implantação e funcionamento de um Parque Arqueológico erguido sobre aquelas ruínas objetivando verificar pontos positivos com vistas ao aproveitamento turístico de outros espaços em ruínas existentes no estado do Rio de Janeiro, estado que devido sua trajetória histórica e social guarda vários vestígios, em forma de ruínas, deste passado. Encerra-se argumentando que desenvolvimento local ocorre efetivamente através de iniciativas que primeiramente atendam aos residentes.

Palavras-chave: Turismo. Memória. Patrimônio. Ruínas.

\section{Abstract}

São João Marcos is an archaeological site formed by the ruins of the city of the same name and whose destruction, to make way for construction of a hydroelectric power plant, promoted eviction process for further flooding of lands; episode that fostered a collective memory of the destruction. In this paper I analyze the experience of implementation and operation of an archaeological park built on these ruins aiming to verify positives overlooking the tourist exploitation of other spaces in existing ruins in the state of Rio de Janeiro, state that because of its historical and social trajectory guard several traces in the form of ruins, this past. I conclude by arguing that local development actually occurs primarily through initiatives that meet the residents.

Keywords: Memory. Heritage. Tourism. Ruins.

\section{Introdução}

O termo ruína deriva do latim e tem em seu significado o sentido de "ruir" ou "cair". Nos termos que estamos pensando nesse estudo, o conceito de ruína está sempre atrelado a uma materialidade arquitetônica, cuja apresentação física pode ser descrita em associação com as categorias "resquício", "vestígio", "destroço" ou "resto" de uma estrutura. Uma ruína, é sempre uma referência do passado; entretanto, assumem no presente diversos sentidos, tais como espaços museológicos, patrimônio cultural e atrativo turístico.

Benjamim (1989) coloca que conjuntos arquitetônicos urbanos estão sujeitos a processos naturais de desgaste, tendendo para um estado de perecimento. $\mathrm{O}$ momento em que processo atinge esse estágio surge a ruína que nas palavras do autor:

“está por desaparecer e esse desaparecimento ilumina, com uma 
luz singular e poética, tudo aquilo que o condenou, seu outro e seu contrário. [...] possibilitando a fantasmagoria daquelas lembranças ou memórias que, como lacunas da história, permanecem para assombrar o presente e alertar sobre o futuro". (Benjamim, 1989)

Ainda de acordo com Benjamim (1985) a ruína se apresenta numa estreita relação com a imagem e o tempo submetendo-se diretamente a ação deste para com a sua imagem, representando segundo o autor uma "síntese paradigmática entre tempo e espaço".

Simmel (1998) percebe as ruínas como resultado de um conflito entre a vontade humana e necessidade da natureza, que se caracteriza entre vida e morte, extremos que une passado e presente, não sendo nem um nem outro. A sedução das ruínas, segundo Simmel, está justamente na natureza que nela ainda persiste, no fato desta ser uma simbologia da ação destruidora da natureza sobre o poder de erguer do homem. $\mathrm{O}$ autor assim afirma:

“... A ruína da obra arquitetônica significa que naquelas partes destruídas e desaparecidas da obra de arte outras forças e formas e aquelas da natureza, cresceram e constituíram uma nova totalidade, uma unidade característica, a partir do que a arte ainda vive nela e do que de natureza já vive nela". (Simmel, 1989)

Simmel e Benjamim evidenciam aspectos que contribuem para delimitar o que sejam ruínas. Prontamente, identificamos o poder evocador do passado presente nas ruínas; nesta condição, as ruínas explicitam a finitude do homem e de seus feitos, evidenciando a transitoriedade desta materialidade. Desta forma, as ruínas habitam simultaneamente dois tempos, o ocorrido e o presente. Nessa perspectiva, a memória atua como elemento indutor e as ruínas adquirem o significado de recordações selecionadas dentre uma gama de tudo o que pode ser recordado. O passado relembrado pode ser individual ou coletivo. De modo geral, o relembrar o passado é crucial para o sentido de identidade, perpetuando uma autoconsciência coletiva tornada oficializada e apoiada na materialidade que se constitui em patrimônio.

Patrimonium, termo de origem latina, em uma perspectiva histórica, esteve inicialmente relacionado aos bens legados pelos pais aos filhos ou por pessoas aos seus descendentes diretos. Posteriormente, o termo passou a ser aplicado ao conjunto de bens que alguma pessoa ou instituição possui e por isso pode-se falar em patrimônio público, patrimônio privado ou patrimônio nacional. O caráter abrangente do conceito permite atualmente a classificação em patrimônio cultural e natural, sendo o primeiro percebido através de variados tipos, tais como arqueológico, industrial, histórico, entre outros; já o patrimônio natural refere-se às formações físicas, biológicas e geológicas excepcionais, habitats de espécies animais e vegetais ameaçadas e áreas que tenham valor científico, de conservação ou estético excepcional e universal. 
Para Choay (2001) a atual conotação de patrimônio está entrelaçada aos atributos acoplados ao conceito de monumento histórico forjado durante a Revolução Francesa. Para a autora, os documentos que justificavam a nacionalização dos bens do clero e da realeza alegam que estes são "patrimônio e herança de todos". Nessa perspectiva, emerge um processo que passou a denominar "patrimônio" ao monumento que foi declarado como um bem de todos. Entretanto, a noção de monumento histórico é mais antiga que a de patrimônio e provém do século XV, quando as ruínas antigas da Roma Imperial passam a ser valorizadas.

Patrimônio enquanto categoria de pensamento, tal como apontou Gonçalves (2003), é polissêmica, envolvendo vários sentidos e assume no mundo moderno três dimensões, pois é categoria jurídica, política pública e instrumento de comunicação social. Nesse sentido, a categoria patrimônio é um potente instrumento analítico para entender a vida social e cultural no mundo atual. Gonçalves também argumenta que o conceito moderno de patrimônio está ligado à existência do Estado Nacional, mas esta relação não seria aparente, principalmente porque o uso em uma variedade de discursos, tais como patrimônio econômico, financeiro, familiar, cultural, arquitetônico, ecológico, etc; naturalizou-o.

Gonçalves (2002) esclarece que o patrimônio é constituído narrativamente como alegoria, isto é, constituído para representar uma coisa cujo sentido era significar outra e exemplifica sua afirmativa abordando a questão da nação cuja constituição se efetivou através do processo de perda, pois a identidade nacional estava sendo construída em meio ao processo de desaparecimento. A nação, vista como objetivada, autorizava o tratamento e a preservação do patrimônio. O patrimônio instituído era ao mesmo tempo produto e produção desta objetivação cultural. A nação enquanto entidade naturalizada, única, servia de referência aos repositórios de significados que seriam utilizados na constituição do patrimônio. Neste sentido foi possível pensar a proteção do patrimônio como proteção da nação.

O fluxo temporal, assim como as mudanças resultantes das reorganizações sociais e históricas, produziu concepções distintas do termo, cujos significados cada vez mais foram incorporando valores até a atual concepção de "bem ou conjunto de bens naturais e culturais de importância reconhecida num determinado lugar, região, país ou mesmo para a humanidade, que passam por um processo de tombamento para que sejam protegidos e preservados". A atual concepção de patrimônio invoca a ideia de algo que deve ser respeitado e preservado, pois a "perda" seria um processo inerente ao que é considerado patrimônio.

O significado da palavra patrimônio passou de tesouro artístico, destinado à con- 
templação por uma minoria de privilegiados, para monumento histórico-cultural, de interesse dos Estados-nação, representativo da identidade nacional que se desejava consolidar; posteriormente, passou a representar culturas. Analisando esse processo de ressignificação do patrimônio, percebemos que sua definição vai além dos valores históricos, artísticos, científicos, educativos e políticos e, incorporam outros, que se relacionam com o território e com a construção da identidade cultural de uma população, sendo essa, uma das características mais relevantes do conceito: ser tomado como referência para a construção de identidades culturais pelas mais diversas estruturas sociais e mesmo pelos cidadãos, em nível individual, de forma a converter-se no capital simbólico da sociedade.

Em Ressonância, materialidade e subjetividade: as culturas como patrimônio (2005), José Reginaldo Gonçalves explica que o patrimônio deve ser entendido como mediador entre mortos e vivos, deuses e homens, nacional e estrangeiro, podendo ser pensando como fato social total, tal como apontando por Mauss. No mesmo trabalho, Gonçalves ainda aponta características inerentes ao patrimônio enquanto conceito moderno. A primeira delas seria a ressonância, isto porque não basta o Estado consagrar um bem como patrimônio, o bem precisa articular ligação do presente com o passado. Outra característica do patrimônio é a sua materialidade, mesmo que seja intangível ou imaterial.

Para o referido autor, o conceito articulado à concepção antropológica da cultura, valoriza as relações sociais e simbólicas e estas no limite podem ser pensadas a partir da oposição entre o material e o espírito, tal como faz Bakhtin (1993), tornando-o indistinto na categoria. A terceira característica giraria em torno da construção das subjetividades, ou seja, o patrimônio por estar ligado ao passado, como algo herdado ao mesmo tempo em que construído/adquirido, tem inúmeras possibilidades de correlações, todas gerando e necessitando de autoconsciência. A reunião dessas características faz do patrimônio uma categoria de pensamento e, consequentemente, um poderoso instrumento de análise da sociedade atual.

A afirmação de José Reginaldo Gonçalves, no que tange ao patrimônio como categoria de pensamento, está relacionada a noção de que o mesmo pode ser associado a um processo social, pois um patrimônio é essencialmente histórico, de modo que seu significado sofre re-elaborações em função de interpretações do presente. No processo de seleção de patrimônios culturais, a história manifesta-se através de um discurso elaborado a partir das condições do presente, que construindo socialmente o passado apoia-se na concretude do patrimônio estabelecendo uma ponte com passado adotado coletivamente. Nessa linha de raciocínio um elemento cultural não é um patrimônio por si mesmo, mas se torna patrimônio através de um pro- 
cesso de construção social. O patrimônio cultural eleito por determinado grupo ou comunidade detêm os elementos considerados representações simbólicas da identidade cultural e se manifestam através da continuidade histórica, por representar um passado cuja ressonância, nos termos proposto por José Reginaldo Gonçalves, está associado ao presente do grupo ou comunidade.

Enquadrada na categoria patrimônio, uma ruína fundamenta, em si, um modo de se conhecer o passado, de preservação da memória, e, por conseguinte, do assim considerado patrimônio nacional. Ao tornar-se parte das estratégias de interpretação do passado, adentram nas políticas de preservação do patrimônio, sendo então, ressignificadas enquanto documento histórico e arquitetônico fortalecendo a ideia de locais a serem preservados, tendo seus usos associados a visitação e ao lazer.

\section{A utilização turística do patrimônio arqueológico}

O uso econômico do patrimônio tem na atividade turística sua maior expressão, pois as identidades culturais, especialmente os patrimônios culturais que as sustentam tornam-se alvo de atração turística, exatamente pelo caráter distintivo do grupo ou comunidade. Os bens patrimoniais constituem referências ou símbolos culturais, alcançando relevância econômica devido a atração que as diferenças entre os grupos promovem. Desse modo, os interesses de preservação de determinados bens, a recuperação de memórias, a construção de identidades fortemente associadas a localidades e à valorização do lugar, estão cada vez mais atrelando interesses econômicos à atividade turística.

Esse conjunto, caso seja desejo dessa comunidade, podem ser interpretados como recursos a serem utilizados como forma de indução ao turismo cultural. Nessa perspectiva, o patrimônio cultural transforma-se em recursos turísticos culturais, pois apresentam uma determinada potencialidade para se tornarem atrativos turísticos culturais.

O uso econômico do patrimônio arqueológico por via do seu aproveitamento turístico e de visitação confere ao bem um novo significado. Essa dimensão mais explicitamente utilitária do patrimônio convive com as dimensões política e simbólica, numa relação de complementaridade e retroalimentação, pois os referentes simbólicos fornecem os motivos que alimentam a indústria turística e a indústria turística recria os elementos culturais e a própria história, emanando novos referentes simbólicos que dão substância à memória coletiva. 
"Lugares de memória" ${ }^{2}$ devem atender a turistas e residentes, pois sua condição primeira é divulgar, circular, tornar conhecido do grande público uma história cujo significado é tão valorizado para determinado grupo que faz com seja parte integrante da identidade do mesmo. Nesse sentido, no que tange a ruínas com potencialidade para aproveitamento turístico e de lazer, o estado do Rio de Janeiro detêm várias possibilidades, entre as quais, destaca-se quatro.

\section{Vila de São João Marcos ${ }^{3}$}

De acordo com Decreto E-18/000.062/90 o tombamento provisório em nível estadual aconteceu no ano de 1990. Porém, a história do processo é anterior. Houve, em 1939, o primeiro tombamento do município de São João Marcos. Este processo foi revogado em 1940 por conta da ampliação do espelho d'água da usina hidroelétrica de Lages, que iria alagar toda a cidade. A inundação ocorreu e a cidade, como consequência, foi transformada em ruínas. Em 1941 a usina hidroelétrica de Lajes indicou que não seria necessário manter as ruínas da cidade submersas. Houve, neste momento, o início de um processo de disputas práticas e simbólicas relacionadas à incorporação das ruínas ao cenário urbano de Rio Claro, município que incorporou o território da antiga São João Marcos. Há um conjunto de agentes sociais envolvidos nesta disputa. São eles: a Light Serviços de Eletricidade S.A., o Instituto Estadual do Patrimônio Cultural - INEPAC, a Prefeitura de Rio Claro representada pela Secretaria de Cultura, além dos movimentos sociais que integravam ex-moradores e seus descendentes, conduzidos pela prefeitura ${ }^{4}$.

O conjunto de disputas pelas ruínas de São João Marcos promoveu a construção e a manutenção de uma série de sentidos associados à cultura local, cultura nacional, patrimônio público e responsabilidade social. Formou-se uma arena pública de disputa onde todos os agentes ativavam seus capitais simbólicos, econômicos, sociais e intelectuais para lutar pela definição do futuro das ruínas da Antiga São João Marcos. O resultado final foi a transformação das ruínas em patrimônio público estadual e a construção do Parque Arqueológico e Ambiental de São João Marcos, franqueado a visitação pública e percebido pelos idealizadores do projeto como produto turístico ${ }^{5}$.

\footnotetext{
2 Para o conceito de lugares de memória, ver Nora (1993).

3 Os dados de cunho histórico aqui apresentados são oriundos de minha pesquisa documental realizada entre os anos de 2009 e 2011 ocasião de coleta de dados para minha tese de doutorado.

40 material de pesquisa aqui apresentado fazem parte do extenso trabalho de campo coletado para elaboração de minha tese de doutorado, desenvolvida no âmbito do Programa de Pós Graduação em Antropologia da Universidade Federal do Rio de Janeiro (IFCS/UFRJ).

5 O Parque Arqueológico e Ambiental de São João Marcos foi idealizado para ser um indutor da atividade turística da região em que está localizado.
} 


\section{Vila do Iguassú6}

A historiografia brasileira, mais especificamente a fluminense, indica que em 1567, os portugueses expulsaram os franceses e seus aliados do território que hoje corresponde à Baixada Fluminense. Nessa época, para minimizar o perigo de novas invasões, Portugal inicia a doação de terras da Coroa (sesmarias). Uma dessas sesmarias, situada às margens do Rio Iguassú, foi doada a Cristovão Monteiro que iniciou as lavouras de arroz, milho, mandioca, feijão e cana-de-açúcar nos terrenos mais enxutos das encostas das serras. Os terrenos pantanosos da baixada, que eram inundados pelos numerosos rios, serviram às primeiras olarias.

Mais tarde, à margem direita do Rio Iguassú, (região que corresponde à porção norte da atual cidade de Nova Iguaçu - RJ) surgiu o povoado que recebeu o nome do rio, Freguesia de Nossa Senhora da Piedade do Iguassú. Devido ao crescimento comercial, em 1833, esse povoado foi elevado à condição de Vila, ocorrendo posteriormente a criação do Município de Iguassú que abrangia inicialmente suas terras, contava com seis freguesias ou distritos: Freguesia de Nossa Senhora da Piedade de Inhomirim, Nossa Senhora do Pilar, São João de Meriti, Santo Antônio de Jacutinga, Nossa Senhora da Conceição de Marapicu e Nossa Senhora da Piedade, onde foi instalada a sede do município.

Os anos entre 1833 e 1891 foram marcados pelo progresso e decadência para Iguassú. Quando o café passou a ser cultivado em larga escala nas fazendas do Vale do Paraíba e da zona Iguassuana, maior foi à prosperidade de Iguassú, que chegou a possuir grandes armazéns e estabelecimentos comerciais que giravam com vultoso capital. A produção de café realizada pelos municípios vizinhos era escoada através dos portos de Iguassú e essa situação conferia importância social e econômica desse local que se apoiava ainda na Estrada Real do Comércio, principal via de ligação entre os portos do Iguassú e à Corte. O declínio da Vila teve início em meados do século XIX quando o café passou a não ser mais escoado pela Estrada Real do Comércio e consequentemente pela não utilização dos portos da região. Naquele momento, o trem a vapor despontava como meio de transporte preferencial e acabava por promover uma mudança no eixo econômico. Assim, as ferrovias substituíram a navegação fluvial e em 1891 a sede do município é transferida para o arraial de Maxambomba, passando a antiga sede a ser denominada Iguassú Velha ou Velho.

Os canais abandonados quando em época de cheias e os brejais sem vazamentos, transformaram-se em excelentes focos dos mosquitos transmissores da malária e o

6 Idem a nota número 1. 
conjunto arquitetônico de Iguassú foi ficando abandonado, sendo posteriormente saqueados já que muitas propriedades foram abandonadas com mobiliários. A extinta Vila de Iguassú fica entre o que é atualmente Vila de Cava e Tinguá, situa-se no vale entre pequenos morros e a grande área alagada que restou do rio Lavapés. Os elementos urbanos da Vila de Iguaçu que restam como vestígios são o Porto de Iguaçu e a torre da Igreja de Nossa Senhora de Iguaçu acompanhada de dois cemitérios. Do antigo cemitério da Vila, resta o local cercado por muro, fachada com data de 1875, em um dos lados e Nossa Senhora do Rosário, no outro. O mesmo está desativado. $\mathrm{O}$ outro, mais atual permanece em funcionamento.

\section{Vila de Nossa Senhora da Estrela7}

A vila de Nossa Senhora da Estrela e o seu porto, localizado às margens do rio Inhomirim, na Baixada Fluminense era passagem obrigatória dos viajantes que se deslocavam para Minas Gerais motivados, em sua maioria, pela busca de ouro. Assim como a Vila do Iguassú e São João Marcos, a Vila de Nossa Senhora da Estrela já teve seu período de prosperidade, contando com igreja, armazéns, cerca de 600 casas e o movimento trazido pelo grande número de viajantes que por ali passavam. A decadência da antiga vila começou com a inauguração da primeira estrada de ferro brasileira, construída pelo Barão de Mauá. A partir da linha férrea, todo o movimento da região foi desviado para a vila de Nossa Senhora de Pacobahyba, na atual praia de Mauá e o porto da Estrela foi se esvaziando, sofrendo com as epidemias e com a falta de atrativos econômicos. Hoje, esse passado é conhecido por poucos e o abandono impera na região. Do cais restam poucos degraus quase imperceptíveis no meio do mato, do posto da alfândega, onde eram controlados o pagamento de impostos incidentes sobre o ouro vindo de Minas Gerais, restaram somente as ruínas da fachada, um vão com três portas. Mais ao longe as ruínas da igreja que já abrigou a imagem de Nossa Senhora da Estrela e, ao fundo, muito pouca coisa do antigo cemitério da vila à qual já pertenceu Petrópolis.

\section{Vila de Santo Antônio de Sá ${ }^{8}$}

A vila de Santo Antônio de Sá nasceu de uma concessão de sesmarias no ano 1567, em terras banhadas pelos rios Macacu e Cassarebu, onde formou-se um povoado. Em 1612 foi fundada uma capela em homenagem ao referido Santo e com 
o crescimento da população houve a recomendação para a construção de um convento no local, o Convento São Boaventura. Assim, as histórias do convento de São Boaventura de Macacu e da Vila de Santo Antônio de Sá praticamente caminharam juntas.

A então freguesia foi elevada a categoria de Vila no ano de 1697, passando a atuar como importante entreposto comercial, abrangendo os atuais municípios de Magé, Itaboraí e Rio Bonito. A decadência da vila teve início com as chamadas febres de Macacu (cólera e malária) ocorridas nos anos de 1828, 1829 e 1836 devido à insalubridade do local, resultante da formação de bancos de areia na foz do rio Macacu e das chuvas que, após um período de seca, levaram ao trasbordamento do rio, inutilizando as terras e dizimando grande parte da população. Desde essa ocasião, freguesias que compunham a Vila foram se desmembrando de Santo Antônio de Sá, moradores não contaminados foram abandonando a região e os frades deixaram o convento, até que a Vila extinguiu-se, restando as ruínas da torre da igreja matriz e do convento. Hoje o centro da Vila está localizado nas terras da Fazenda Macacu, cuja propriedade é particular.

O Convento São Boaventura teve seu estabelecimento a partir do recolhimento de religiosos em acampamentos localizados na Vila de Santo Antônio de Sá no ano de 1649. No ano de 1650 a comunidade franciscana passou a ocupar esse espaço permanecendo até 1670, data do término da construção do Convento, cujo inicio da edificação remonta o ano de 1660. Após várias intervenções nas edificações, a de 1788 configura a que se encontra em ruínas existentes nos dias de hoje. A decadência do Convento São Boaventura, assim como a da Vila de Santo Antônio de Sá, iniciou-se com os surtos de malária e cólera. Documentos da época registram que o abandono total do Convento ocorreu no ano de 1841.

As ruínas do Convento São Boaventura, localizadas atualmente no distrito de Porto das Caixas, Itaboraí-RJ, foram são tombadas pelo tombadas pelo INEPAC em 1978 e pelo Instituto do Patrimônio Histórico e Artístico Nacional (IPHAN), em 1980. As ruínas do Convento São Boaventura encontram-se em área do Complexo Petroquímico do Rio de Janeiro (Comperj-Petrobras) e o espaço não é aberto à visitação.

\section{Bens tombados das extintas Vilas}

A Vila de Santo Antônio de Sá (atualmente localizada município de Itaboraí - RJ), a Vila de São João Marcos (atualmente localizada no município de Rio Claro - RJ), Vila de Iguassú (atualmente localizada no município de Nova Iguaçu - RJ) e Vila de 
Estrela (atualmente localizada no município de Magé - RJ), foram importantes no processo de ocupação do solo Fluminense, mas desapareceram em meio a crises econômicas, epidemias e ao abandono dos portos depois do advento das estradas de ferro, quando deixaram de ser rotas para o comércio entre o interior a capital.

De Santo Antônio de Sá, foram tombadas as ruínas do convento São Boaventura (conhecidas como ruínas do convento de Macacu), que de acordo com a avaliação do INEPAC: "Envolvidas por um cenário natural de extrema beleza, as ruínas do convento se destacam majestosas no sítio, onde existiu no século XVIII a antiga Vila de Santo Antônio de Sá. Apresenta o mesmo partido arquitetônico do convento de Santo Antônio, na Cidade do Rio de Janeiro - casa conventual, torre sineira, igreja e capela da Irmandade - ambos da ordem franciscana. Em 1874 iniciou-se a construção da igreja da Ordem Terceira. De 1829 a 1840, uma epidemia dizimou a população da Vila e causou o abandono do Convento pelos franciscanos. Em 1922 as ruínas passaram aos beneditinos e, posteriormente, as terras foram vendidas a diversos proprietários." Registradas sob o Número do Processo E-03/33.714/78, tem seu Tombamento Provisório decretado em 11.12.1978 e atualmente, a extensão de terras onde o convento está localizado pertence a Empresa Brasileira de Petróleo (PETROBRAS).

Da extinta Vila do Iguassú, o INEPAC tombou (Número do Processo: E-03/02.453/78 e Tombamento Provisório: 08.04.1983) o Conjunto urbano da extinta Vila de Iguaçu (Hoje conhecida como Iguaçu Velha). Segundo o INEPAC, Iguaçu Velha guarda vestígios da história da colonização do sertão fluminense, iniciada em 1567. Dos vários portos construídos ao longo do rio Iguaçu destacava-se o Porto do Feijão. No final do século XIX e início do XX, os surtos frequentes de doenças tropicais provocaram a extinção de Vila de Iguaçu. A paisagem atual é marcada pelas ruínas da Matriz de Nossa Senhora da Piedade, de fins do século XVII e do muro do cemitério, pelos alicerces de antigas construções e vestígios do porto. $\mathrm{O}$ bem tombado está situado no Terceiro Distrito de Nova Iguaçu, Vila de Cava.

\section{A experiência do Parque Arqueológico e Ambiental de São João Marcos}

A discussão sobre processos de tombamento envolvem não somente o aspecto da proteção e salvaguarda de algo socialmente percebido como detentor de um valor, abrange também o debate acerca da utilização e manutenção de bens tombados. Nesse ponto, um dos usos mais difundidos do patrimônio nos últimos anos envolve o turismo, seja mediante a instalação de meios de hospedagem ou rede de alimentação ou ainda a visitação paga. Assim, a experiência do Parque Arqueológico e 
Ambiental de São João Marcos contribui para o debate acerca da utilização turística de ruínas.

A cidade de São João Marcos, que havia sido tombada pelo Serviço de Patrimônio Histórico e Artístico (SPHAN) em 1939 teve seu tombamento federal revogado no ano de 1940, sendo demolida para dar lugar a uma represa, após a retirada seus moradores que, ainda hoje, recordam com saudade a sua terra natal ${ }^{9}$. O local, abandonado e deixado a ação do tempo, guardando as ruínas que materializam as memórias dessa ocorrência, foi alvo de um processo de revitalização. No no ano de 2008, o Instituto Light ${ }^{10}$ com patrocínio da Secretaria de Cultura, através da Lei de Incentivo à Cultura, e apoio do INEPAC, da Prefeitura de Rio Claro, do IPHAN e do INEA; iniciou o projeto de construção do Parque Arqueológico e Ambiental de São João Marcos, sendo esse um espaço organizado em termos de um circuito turístico, que viesse a "reforçar os significativos atributos turísticos já ali existentes". O projeto piloto incidiu na construção do Parque Arqueológico e Ambiental de São João Marcos em uma área de 930 mil metros quadrados que cobre toda a extensão da antiga cidade e trechos importantes da outrora Estrada Imperial. De acordo com o Instituto Light, o objetivo do projeto e consequentemente do Parque, é contribuir para a conscientização, educação e lazer da população do Vale do Paraíba.

O projeto em tela foi divido em fases, sendo a primeira marcada pelas ações resultantes das pesquisas relativas à história, a iconografia e ao ambiente físico; a coleta de depoimentos de pessoas que haviam residido no local e; prospecção arqueológica. Essas pesquisas embasaram a elaboração dos seguintes sub-projetos: a) projeto arqueológico cujo objetivo foi tornar visível a estrutura elementar da Cidade no intuito de favorecer as vias de circulação e os perímetros de suas edificações. Visava expor ainda as estruturas da antiga Estrada Imperial nos trechos mais próximos a Cidade; b) o projeto ambiental incide especialmente sobre a área de proteção da Represa de Ribeirão das Lajes; c) projeto museológico abrange três espaços distintos: o Centro de Memória, a Área de Guarda e o Circuito de Visitação do Parque. Este projeto possui apelo turístico e educativo, pois segundo o Instituto Light, "nestes espaços pretende-se oferecer aos visitantes a oportunidade de trazer para o presente as memórias impregnadas nos fragmentos e ruínas encontrados nas escavações

\footnotetext{
9 Para aprofundamento do processo de elaboração memorial do episódio do tombamento, revogação deste ato e demolição da cidade de São João Marcos, ver Oliveira, Maria Amália (2012).

10 O Instituto Light é uma organização financiada pela Light. A principal missão desse Instituto, conforme conta no site da Empresa é: "Contribuir para o aprimoramento das condições econômicas e sociais da área de concessão da Light, através de programas que vinculem responsabilidade social com o interesse funcional e o domínio geográfico da empresa, apoiando a promoção do bem público e, ao mesmo tempo, a lucratividade de longo prazo da empresa."
} 
arqueológicas, nos documentos, fotografias, objetos e depoimentos"; d) o projeto arquitetônico elaborado para atender três objetivos principais: acolhimento ao público visitante, a exposição sobre a memória da Cidade e a guarda e conservação dos documentos e objetos originais. Essa primeira fase compreendia o período entre os anos 2008 e 2010, quando no mês de março ocorreria a inauguração do Parque.

O Parque foi inaugurado no dia 09 de junho de 2011; mas, antes mesmo da inauguração, isto é, no período entre março de 2010 e maio de 2011, já pronto, o Parque recebeu "alunos-visitantes" oriundos dos programas de visitação escolar. De acordo com o estipulado no projeto museológico do Parque, inicialmente as visitações se destinariam para o público de alunos de escolas públicas da região, atividade inserida no programa educativo constate no projeto inicial e cuja elaboração tem como meta promover a valorização da memória local. Entretanto, o Parque também recebeu cerca de 600 visitantes ${ }^{11}$, que atraídos pela "novidade", solicitaram autorização para realizar o percurso que compõe o circuito de visitação. Vale ressaltar, que esse número de visitantes dirigiu-se para o local de forma espontânea, pois não há um programa de publicidade e marketing ostensivo. O circuito mínimo de visitação ocupa uma área de 33 mil metros quadrados, onde se localizava o centro populacional da antiga cidade. Durante as visitações, são distribuídas cartilhas explicativas e disponibilizados guias especializados para acompanhar os alunos-visitantes.

A segunda fase abrangeria os anos de 2010 a 2015 prevendo a continuidade dos trabalhos iniciados na fase anterior e seria marcado pelo momento em que o Parque passaria a "explorar seu potencial ecológico e de lazer, oferecendo trilhas, passeios de barcos, etc. A partir de 2010, quatro festas populares anuais, identificadas com a região e sua história, reunirão os moradores na Cidade ${ }^{12 "}$. O Instituto Light estabeleceu como meta que a partir de 2015, o Parque já tenha conquistado sua "auto-sustentabilidade", resultante dos esforços empreendidos pela Light, a Eletronuclear, a Secretaria de Estado de Cultura, INEPAC, Prefeitura de Rio Claro, parceiros regionais, investidores e de receitas oriundas do empreendimento. $O$ projeto enfatiza como primordial no conjunto de ações e atividades previstas o "crescimento econômico e social da região, organizado dentro de um Plano de Negócios que visa a auto-sustentabilidade do Parque." (Material de divulgação do Parque)

Nesse momento, o funcionamento do Parque está centrado em atividades pedagógicas voltadas para alunos de escolas públicas da região e pretende ser uma ferramenta de auxílio para a construção do conhecimento através da percepção da

11 Número fornecido por um 'informante' ligado ao Projeto de implantação do Parque Arqueológico e Ambiental de São João Marcos e funcionário do Instituto Light.

12 Material de divulgação do Parque Arqueológico e Ambiental de São João Marcos - Light. 
realidade concreta. Uma das formas de colocar a aprendizagem num círculo bem mais amplo é permitir que os alunos entrem em contato com as realidades distintas e com a sociedade como um todo, sendo um caminho para esse contato a realização de "estudos do meio". O estudo do meio é uma prática de ensino que se constitui como elemento fundamental da interdisciplinaridade e interação do aluno como um meio qualquer, assemelhando-se nessa perspectiva à atividade turística, pois o estudo do meio visa transformar as aulas em passeios, transportando os alunos para diferentes lugares, com a finalidade de estudo. As "aulas-passeio" colocariam os alunos em interação com o meio, gerando um círculo de relações sociais, econômicas e culturas interligadas, as quais permitem caracterizar esse tipo de atividade como uma forma de lazer e turismo aplicados à educação.

Após o relato da experiência do Parque Arqueológico e Ambiental de São João Marcos, pontua-se no próximo item elementos que me relevantes para o sucesso de empreitadas semelhantes, tendo em vista o potencial de ruínas existentes no estado do Rio de Janeiro, tais como as anteriormente citadas e outras aqui não enumeradas.

\section{Circuitos de visitação em espaços arqueológicos como ferramenta de divulgação e preservação da memória e da história}

Para que um recurso esteja efetivamente capacitado a atrair turistas é necessário o envolvimento da comunidade e a articulação entre educação e conservação patrimonial. A experiência de São João Marcos tem se mostrado bem sucedida especialmente por direcionar-se inicialmente aos moradores do entorno, ao privilegiar alunos de escolas da região. Ao agregar os pilares do fenômeno turístico, isto é, o deslocamento e a presença no local, aliados a educação e ao lazer, temos uma excelente possibilidade de indução à uma atividade turística sustentável.

A referida experiência revela que a recuperação e registro de memória sobre as ruínas de conjuntos arquitetônicos de antigas Vilas localizadas no estado do Rio de Janeiro devem estar apoiadas em um projeto sobre memórias coletivas, pois como pontuado por Gonçalves em obra anteriormente citada (2005) faz-se necessário que haja a ressonância para que o patrimônio seja legitimado pelo grupo social que o abriga. Tal empatia torna-se imprescindível pelo entendimento de que as ruínas enquanto resquícios tornam-se inteligíveis tornando-se capazes de serem apreciadas somente quando acompanhadas de uma narrativa. Essa narrativa apoia-se na memória coletiva que lhe dá significado e, por esse prisma, a memória coletiva seria o "escultor" das cidades que já desapareceram e tornam-se invisíveis quando a memória coletiva não lhes conte sua história: 
... a história dessas ruínas conta uma parte da história do Brasil, de suas lutas políticas, dos momentos de auge e decadência econômica e das obras que em nome do progresso passaram por cima de aspectos humanos e identitários intrínsecos a elas. Através destes fragmentos, trazemos à vida essas cidades, fazendo ver a importância do tombamento dos bens fluminenses e a luta pela preservação de suas memórias". (Trecho retirado do vídeo Cidades Invisíveis)

Outro ponto que merece atenção na experiência em análise diz respeito a proposta de musealização do espaço. O Parque Arqueológico e Ambiental de São João Marcos é classificado por seus idealizadores como um museu de território, sendo desta forma, subordinado a parâmetros específicos de proteção, documentação, estudo e interpretação. $O$ projeto museológico do Parque incide sobre três espaços distintos: o Centro de Memória, a Área de Guarda e o Circuito de Visitação do Parque. A estratégia de musealizar o Parque teve como objetivo a manutenção da memória impregnada nos fragmentos e ruínas encontrados nos trabalhos arqueológicos, nos documentos, fotografias, objetos e depoimentos coletados durante o processo de prospecção arqueológica.

Por musealização entende-se a elaboração de um sistema estético para criar significados. Em outras palavras, a musealização diz respeito à preservação e à comunicação, sendo também um ato através do qual um artefato é privado de suas funções originais, passando a cumprir a função de documento. Os dois modelos museológicos voltados para a musealização do patrimônio arqueológico são: os museus arqueológico-artísticos, estruturados em torno de análises estéticas, no âmbito da história da arte, em geral "vocacionados para a preservação das coleções da Antiguidade Clássica, ou das culturas andinas e mesoamericanas" e os "museus arqueológico-tecnológicos, responsáveis pela musealização dos vestígios pré-históricos e vinculados aos estudos da antropologia e das ciências naturais", cuja ênfase, em geral, recai no contexto. De novos processos de musealização resultaram os "museus ao ar livre, museus comunitários, ecomuseus, museus de cidade, museus de território, museu de sociedade, entre outros, são igualmente integrados por acervos arqueológicos".

Já a Museografia é definida como "as técnicas e procedimentos do fazer museal em todos os diferentes aspectos, tais como: construção, catalogação, organização e instalação dos fundos-orçamentos." A museografia concretiza as idéias que se deseja expor. Nesse sentido, cada museu, cada ambientação e distribuição de espaço é portadora de uma ideologia que é narrada através da elaboração museográfica.

Nesse intuito, o projeto museológico previu que os recursos museográficos utilizados privilegiassem o dinamismo e, assim, no Centro de Memória o visitante encon- 
tra informações sobre a história social, política, econômica, urbana e cultural de São João Marcos. Para tal, são utilizados recursos audiovisuais, exibição de depoimentos coletados durante os trabalhos arqueológicos e nos quais são narradas histórias de vida e memórias de moradores da cidade, sonorização baseada em trechos de cantigas de roda, cânticos religiosos e marchinhas de carnaval. Todo o aparato utilizado pela museografia aplicada ao ambiente visa "trazer de volta as vozes do passado e o clima festeiro dos marcossenses." Soma-se aos recursos audiovisuais e sonoros o apelo ao visual que se dá através da utilização de painéis suspensos, dois tipos de vitrine verticais e embutidas e a maquete que reproduz a cidade de São João Marcos na década de 30-40 do século XX.

Por último, um terceiro aspecto chama a atenção no Parque Arqueológico e Ambiental de São João Marcos: o projeto de educação patrimonial desenvolvido para o Parque. A teoria da educação patrimonial reconhece como principio básico que os indivíduos aprendem melhor por meio da vivência de experiências diretas com bens do patrimônio. Por este motivo, suas atividades têm sido utilizadas na mediação de visitas a sítios patrimoniais, nos moldes de "circuitos turísticos", cujas atividades quando bem organizadas garantem a compreensão do visitante sobre o sítio visitado, tornando-o capaz de desfrutar de sua visita e contribuir para a preservação do local. Diante da concepção de um relacionamento onde o turista é um aliado da preservação do patrimônio, está calcado no caráter educativo das práticas ocorridas durante a visitação. $O$ caráter educativo aplicado as visitas visa assegurar que o valor e o significado dos recursos favoreçam o conhecimento da memória e da história local e a experiência direta durante a visitação sedimenta esse conhecimento contribuindo para que o visitante seja além de um propagador dessa história e memória, um agente de preservação, devido ao grau de envolvimento que a experiência é capaz de invocar.

A promoção do desenvolvimento sustentável é o principal desafio da educação patrimonial, pois o processo educativo é fator estratégico para estabelecer a sustentabilidade. No entanto, a ação educativa por si só não é suficiente para enfrentar o desafio da proteção do patrimônio. Para ser bem sucedida, a experiência de visitação em um sítio arqueológico (ou qualquer outro espaço que utilize turisticamente os recursos identificados como patrimônio), deve ser norteada por processos que envolva o visitante em uma conscientização da preservação desse bem. Nesse sentido, as estratégias de educação patrimonial devem ser iniciadas com uma reconstituição da história local, antecedidos pela pesquisa, a obtenção de dados e a disseminação da informação. A esse momento sucede o desenvolvimento de materiais de ensino-aprendizagem, cuja proposta deve obedecer aos seguintes objetivos: promover a consciência sobre o patrimônio cultural, sensibilizando os visitan- 
tes para essa questão; apresentar a diversidade de experiências e compreensão do patrimônio cultural; apresentar valores que estimulem os visitantes a participarem ativamente da melhoria e da preservação do bem patrimonial.

Os processos que envolvem a educação patrimonial podem ser formais e não formais. A educação patrimonial formal é a desenvolvida no âmbito dos currículos das instituições de ensino públicas e privadas, em todos os níveis. A educação patrimonial não formal é entendida como as ações e práticas educativas voltadas à sensibilização da coletividade sobre as questões patrimoniais, que deve, entre outros aspectos: difundir, por meio dos meios de comunicação de massa, de programas e campanhas educativas, e de informação a respeito do patrimônio cultural; a participação de empresas públicas e privadas no desenvolvimento de programas de educação patrimonial em parcerias com outras organizações públicas e privadas; a sensibilização, por quaisquer meios, da sociedade para a importância do patrimônio cultural; a sensibilização patrimonial das populações tradicionais.

A educação patrimonial é a base para a preservação de patrimônios culturais e, portanto, torna-se fundamental a inclusão da população local em programas educativos. Desse modo, as populações envolvidas terão maior conhecimento sobre a realidade do ambiente em que vivem e poderão escolher diferentes alternativas para o desenvolvimento entre algumas que surgirão após compreenderem que há outros usos para os recursos patrimoniais, além de sua exploração direta.

\section{Considerações finais}

As ruínas são testemunhos objetivos da vida passada de um povo. Em torno delas se formam memórias e histórias que são transmitidas de geração a geração. Esses monumentos arqueológicos desempenham um papel importante na reconstrução do passado dos povos e grupos sociais. O estado do Rio de Janeiro possui, devido ao percurso histórico e social que caracteriza sua trajetória, um conjunto expressivo de ruínas que podem contribuir para a recuperação da memória e história de distintos grupos sociais. Esse potencial, quando integrado a um circuito mercadológico, favorece a preservação do bem pelo recurso gerado através da renda oriunda da comercialização de serviços e produtos que cercam o bem em exposição.

Para que o ingresso e a permanência no circuito mercadológico não seja prejudicial ao bem, isto é, a ruína, experiências como a do Parque Arqueológico e Ambiental de São João Marcos são interessantes de serem observadas, pois nessa experiência aliou-se o envolvimento da população local, através da recuperação da memória coletiva; um projeto museal coerente e adequado ao que se desejava transmitir em 
termos de conteúdo histórico e memorial e; um programa de educação patrimonial. Tais elementos quando aplicados a realidades que contenham o mesmo apelo de atração, são potentes instrumentos de indução a processos turísticos sustentáveis, pois o desenvolvimento local inicia-se com ações de cunho local e não externas ao cotidiano das comunidades que irão abrigar o fenômeno e a atividade turística.

\section{Referências Bibliográficas:}

BAKHTIN, Mikhail. A cultura popular na Idade Média e no Renascimento. São Paulo: Hucitec, 1993.

BENJAMIN, Walter. Magia e técnica, arte e política. Tradução de Sérgio Paulo Rouanet. São Paulo: Brasiliense, 1985.

. Charles Baudelaire, um lírico no auge do capitalismo. In: Obras

Escolhidas III. São Paulo: Brasiliense, 1989.

CIDADES INVISÍVEIS (vídeo). Documentário de Beth Formaggini. Produzido por Governo do Estado do Rio de Janeiro, Secretaria de Cultura do Estado do Rio de Janeiro e Instituto Estadual do Patrimônio Cultural. 2011

CHOAY, Françoise. A alegoria do patrimônio. São Paulo: Editora da UNESP, 2001.

GONÇALVES, José Reginaldo. Monumentalidade e Cotidiano: os patrimônios culturais como gênero discursivo. In: Lucia Lippi Oliveira (Org.). Cidade: história e desafios. Rio de Janeiro: FGV. 2002.

. O patrimônio como categoria de pensamento. In: Abreu, Regi-

na M. R. M. e Chagas, Mario de S. (Org.). Patrimônio e Memória: ensaios contemporâneos. Rio de Janeiro: DPA/FAPERJ. 2003.

- Ressonância, materialidade e subjetividade: a cultura como pa-

trimônio. In: Horizontes Antropológicos. Volume: 11. Número: 23. Porto Alegre. 2005.

NORA, Pierre. Entre Memória e História. A problemática dos lugares. Projeto história (10). Revista do PPG-Hist/Depto. História/PUCSP, São Paulo,1993.

OLIVEIRA, Maria Amália Silva Alves de. Memória, patrimônio e turismo: a biografia cultural das ruínas do conjunto arquitetônico de São João Marcos (RJ). 2012. Tese (Doutorado) - Instituto de Filosofia e Ciências Sociais, Universidade Federal do Rio de Janeiro, Rio de Janeiro, 2012.

SIMMEL, George. A ruína. In: SOUZA, Jessé (Org). Simmel e a modernidade. Brasília: Editora Universidade de Brasília, 1998. 